\section{After the two cultures}

Adam Kuper

Academic Tribes and Territories: Intellectual Enquiry and the Cultures of Disclplines. By Tony Becher. Open University Press: 1989. Pp.200. Hbk £27.50, pbk £9.95.

TONy Becher's enquiry into the mores of academics is a belated reaction to C.P. Snow's division of intellectual life into two great camps, arts and science, which (if they ever existed) have now long been abandoned for smaller, more intimate, redoubts. An anthropologist, Clifford Geertz, has pointed out that "most academic communities are not that much larger than most peasant villages and just about as ingrown", with their characteristic totems, initiation ceremonies and ancestor rites, modes of work, codes and systems of authority. Professor Becher pursues Geertz's suggestion that these societies should be treated rather in the way that anthropologists study exotic tribes, as social units that have distinctive cultures.

For his enquiry he selected 12 disciplines - biology, chemistry, physics and mathematics, representing the pure sciences; mechanical engineering and pharmacy, as applied sciences; economics and sociology, from the social sciences; history and modern languages from the humanities; and law, representing the social and administrative professions. It is immediately obvious that these categories are not watertight (mathematics, economics and history could all be reclassified), and Becher's thesis is in fact that the most significant criteria for classifying academic pursuits cut across not only the science-arts divide but also disciplinary boundaries, and that they define most clearly the subdisciplines which we call specialisms. This is where the academic has his true being.

Becher's main criteria are familiar: hard versus soft, and pure versus applied pursuits. Hard specialisms use quantitative rather than qualitative methods, clearly define problems and deliver cumulative additions to a body of knowledge. They also tend to be free of value conflicts. Soft specialisms use qualitative methods, address diffuse issues which are often dictated by social concerns (and therefore invite political controversy) and they do not usually yield a body of uncontested knowledge. A more original distinction is that between 'hard, applied' specialisms, which proceed by trial and error, and deliver products which are assessed in terms of their efficiency, and 'soft, applied' professions which use case law, are evaluated in political and moral terms, and produce protocols rather than instruments. Most interesting is Becher's distinction between 'rural' and 'urban' specialisms, the urban specialism being one in which large numbers of workers, operating in competitive teams, address the same closely defined problems, publishing rapidly and often informally, while the rural worker practises his individual craft in a village workshop, where the postman seldom calls.

By applying these criteria to subdisciplines, Becher captures something of the perceived reality of academic life, where the most sensitive boundaries are often drawn within the discipline. He quotes biologists on biologists - "microbiologists are narrow, but geneticists are lively"; "zoologists are more adventurous and less conventional than botanists" but tend to be "arrogant and overconfident"; botanists "hide behind herbarium cases and hate one another". These stereotypes point to some real differences between specialisms which have to do at once with the type of work involved and with the type of people who choose that sort of work (or who are moulded by what they do).

The cultural peculiarities of the tribe are also a matter of organization. Careers, for example, follow characteristic trajectories in particular disciplines. The phenomenon of burn-out, the scientific menopause, which pushes middle-aged men into administration, or philosophy, is most characteristic of hard, pure specialisms. In soft, pure fields scholars become more expert with time, so that a historian may expect to reach his peak only in his fifties. Publications take a different form in different fields. Soft, pure fields typically require books, while hard, pure fields know only short papers. The former are typically written by one scholar over many years, the latter by teams of collaborators on short-term projects. Soft disciplines tend to be dominated by a small number of Grand Old Men, the hard disciplines are multi-centred, throwing up charismatic leaders with shorter tenure and more rivals.

Of course, all academic disciplines also share in the general academic culture, about which Becher has some useful reminders, starting with one of the universals of academic life, "that nearly everything is graded in more or less subtle ways".

His central premise is that "the main currency for the academic is not power, as it is for the politician, or wealth, as it is for the businessman, but reputation". Academic reputation depends on the quality of publications, but it is also affected by institutional affiliation. Publications emanating from famous laboratories or think-tanks start life with a silver spoon in their mouths. Reputation in turn brings
Selected titles from Kluwer

Climate and Geo-Sciences

A Challenge for Science and Society in the 21st Century

Proceedings of the NATO Advanced Research Workshop held in Louvain-laNeuve, Belgium, May 22-27, 1988

edited by A. Berger, S. Schneider and J. Cl. Duplessy

NATO ADVANCED SCIENCE INSTITUTES SERIES

This book presents a series of expert reviews of recent progress in many climate-related disciplines. The future is also signposted, with contributions on emerging technologies.

1989, $728 \mathrm{pp}$.

Hardbound Dfl. 265.00/£88.00/US\$134.00 ISBN 0-7923-0404-7

Paperback Dfl. 140.00/£46.00/US $\$ 69.00$

ISBN 0-7923-0412-8

\section{Artificial Intelligence: Its Scope and Limits}

\section{by James $\mathbf{H}$. Fetzer}

This work explores the philosophical foundations of $\mathrm{Al}$ from the perspective of the theory of knowledge. It makes a sustained, systematic and original contribution to defining the nature of this field.

$1990,325 \mathrm{pp}$.

Hardbound Dfl. 160.00/£53.00/US\$69.00

ISBN 0-7923-0505-1

Paperback Dfl. 69.00/£23.00/US\$29.00

ISBN 0-7923-0548-5

\section{Analog VLSI Implementation of Neural Systems}

edited by Carver Mead and

Mohammed Ismail

THE KL UWER INTERNATIONAL. SERIES IN ENGINEERING AND COMPUTER SCIENCE 80

In Analog VLSI Implementation of Neural Systems Carver Mead and Mohammed Ismail present leading research contributions encompassing the entire range of topics currently under study in this exciting new discipline. All contributors' descriptions include detailed characterization of a working chip. Furthermore, no design has previously been published. As a result, this volume presents the most recent innovative work in this emergent field. Each contribution devotes considerable attention to design shortcomings, as well as to notable successes achieved.

1989, 272 pp. ISBN 0-7923-9040-7 Hardbound Dfl. 150.00/£39.25/US\$55.00

\section{Transition Metal Complexes as Drugs and \\ Chemotherapeutic Agents}

\section{by Nicholas Farrell}

CATALYSIS BY METAL COMPLEXES 11

Aspects of both chemotherapy and pharmacodynamics are included and the book unites for the first time in one volume a description of the wide range and applicability of metal complexes.

1989, $304 \mathrm{pp}$ ISBN 90-277-2828-3 Hardbound Dfl. 180.00/£59.00/US $\$ 89.00$

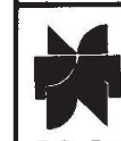

\section{KLUWER ACADEMIC PUBLISHERS}

P.O. Box 322, 3300 AH Dordrecht,

The Netherlands

P.O. Box 358, Accord Station, Hingham, MA 02018-0358, U.S.A.

Reader Service No.38 
power over the careers and reputations of others. Within the political systems of disciplines and specialisms, peer groups may serve as democratic controls, particularly in reviewing, but power tends to concentrate in very small networks.

Suggestive though it is, this short study is nevertheless only a preliminary excursion into the field. Becher restricts himself to élite institutions. His fieldwork was done in Britain and the United States, but he gives an undifferentiated account of the Anglo-American university world, although the national variations are surely very striking. A future study, more sensitive to the national character of academic enterprises, should also consider Dutch, German or Scandinavian universities, with their civil service cultures, or European think-tanks, like the Max-Planck Institutes, on which Nature has been publishing some unsettling ethnographic reports. A reading of Pierre Bourdieu's Homo Academicus, a dense and original recent study of the French academic system, will convince the foreigner that they do things very differently in France. For the purposes of Becher's argument, it is, for instance, noteworthy that the prestige hierarchy of disciplines diverges from the Anglo-Saxon model, and also that the leading research teams are to be found outside the university sector.

Becher does not draw together his scattered comments on the connections which might be made between the peculiarities of various academic tribes and the nature of the territories they inhabit. Here again a comparative approach would have suggested fresh questions. Are German physicists more like German economists in their career patterns and organizational hierarchies than they are like American physicists? Or is it something about physics, or economics, that is decisive? Professor Becher briefly discusses the different environments of the various disciplines - the market pressures on engineers, the professional demands made of lawyers and so forth. But these also vary between different national political systems and markets, as may be seen from the contrasting views of academic engineering in Britain and in Germany.

One important implication of the study is nevertheless clear. These various enterprises are not readily measured by the same criteria because they differ so markedly (and probably necessarily) in their goals, methods, work habits and relationships to the outside world. Bureaucrats will have to refine their measures of efficiency if they are to do justice to this diversity of academic society.

Adam Kuper is in the Department of Human Sciences, Brunel University, Uxbridge, Middlesex UB8 3PH, UK.

\section{Gossip value}

\section{Lewis Wolpert}

Life Among the Scientists: An Anthropological Study of an Australian Sclentific Community. By Max Charlesworth, Lyndsay Farrall, Terry Stokes and David Turnbull. Oxford University Press, Australia: 1989. Pp.304. Pbk A\$19.95. To be published in Britain and the United States next year.

A MEASURE of one's understanding of other groups is how well you appreciate their humour. This applies as much to scientists as any subset of people, for jokes and wit are a prominent feature of laboratory and institutional life. Yet humour is
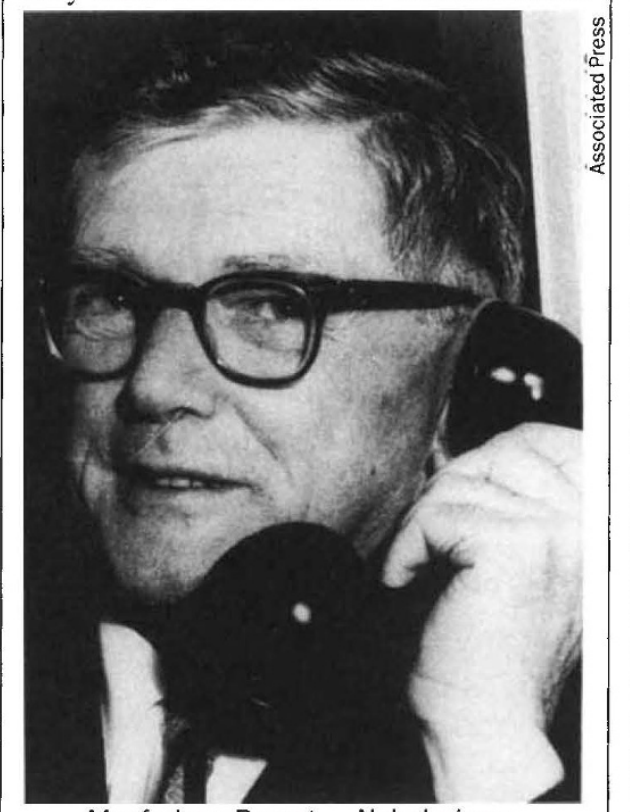

Macfarlane Burnet - Nobel winner.

not mentioned in this book. The scientists at the Walter and Eliza Hall Institute of Medical Sciences in Melbourne - the group considered - may of course be unusual, but a more likely explanation is that the social scientists who carried out this anthropological survey simply failed to understand much of what they were studying.

The authors, who have adopted the curious convention of writing in the first person, like a conflated committee, set out with the provisional hypothesis that scientific knowledge is socially "constructed'. This is a fashionable view among many sociologists of science and implies that science has rather little to do with the real world that scientists study, but instead is shaped by a complex set of social factors. This relativist stance is then used to argue that scientific knowledge has no particular virtue or validity. These authors take a more equivocal position but basically stick to this idea, and the possibility that science provides understanding of natural phenomena is virtually ignored.
The Walter and Eliza Hall Institute is very distinguished, its contributions to science covering a wide range of topics in molecular and cellular immunology. The first director (1944-1965), Sir Macfarlane Burnet, won a Nobel prize for his clonal selection theory and in the book there is an attempt to view him as a local hero whose social function is to legitimize a particular conception of science - the idea of an individual scientist making a discovery which revolutionizes the field. Burnet was hostile to molecular biology and his general style is contrasted with that of the current director, Sir Gus Nossal. But the analysis provides no insight into how Burnet came to make his great discovery or into the basis of his antipathy to molecular biology. It may not have been his dislike of complex apparatus and expensive equipment, as Charlesworth and his colleagues suggest, but rather his inability to see the power of molecular biology. He simply did not believe that it would be possible to understand cells in molecular terms - they were, for him, impossibly complex.

One of the main conclusions of the study is how large a part 'power' plays in the scientific process, for example in what the authors call the legitimization of molecular biology. They are persuaded that Foucault's insight is "profoundly true", namely that the establishment of specific discourses - ways of speaking and thinking - also provides access to power and control over the objects of those discourses. For them "the new model that came to dominate biology after the discovery of DNA only became established after a good deal of politicking and propaganda", in which 'public relations' used by scientists had a large part. The brief analysis of this period is most unsatisfactory and fails to take into account the change in paradigm from metabolism to information. The authors also do not understand the revolution molecular biology caused, and instead concentrate on the idea that molecular biology was a philosophical movement based on the conviction that all biology could be explained in terms of physics and chemistry. Thus it is said that Crick used Schrödinger's name to legitimize his reductionist approach. Of course there was evangelizing and politicking but none of that would have been effective had molecular biology not provided fundamental new insights. Moreover, scientists are aware of these issues and the nature of scientific politics, fashions and power. That's what they often gossip about.

There is a touching, but nevertheless irritating naivety to the conception of science purveyed in the book. For example, the authors are apparently appalled by "the contradiction between the ideal norms of science, that scientific knowledge should be disinterested 